Revista Eletrônica do Mestrado em Educação Ambiental

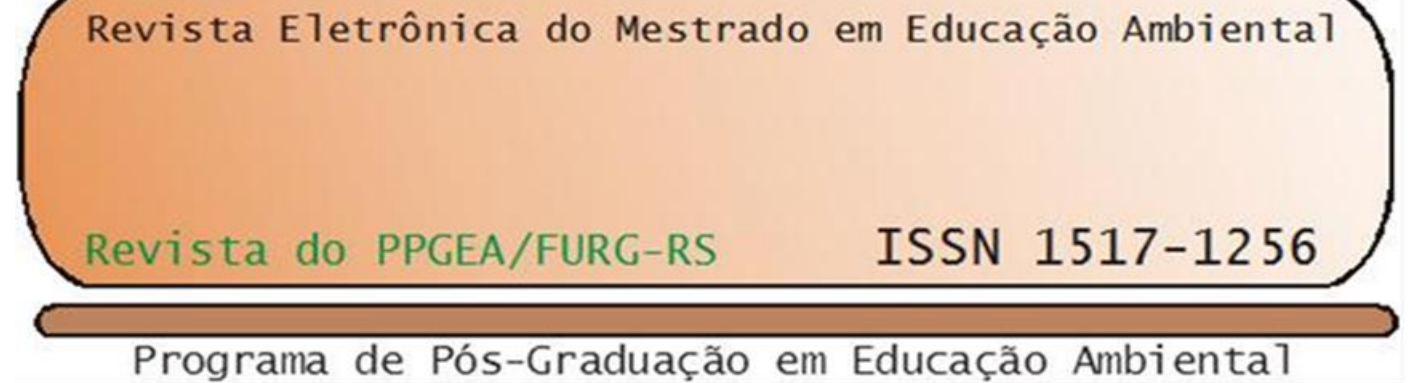

\title{
“Pequenos indígenas" da Tekoá Pindó Mirim e os entrecruzamentos com a natureza: contribuições para o campo da Educação Ambiental
}

\author{
Luana Santos da Silva ${ }^{1}$ \\ Narjara Mendes Garcia ${ }^{2}$
}

Resumo: O presente artigo apresenta uma abordagem acerca da infância na contemporaneidade e seus entrecruzamentos com a natureza, na perspectiva da Sociologia da Infância, da Antropologia da criança e das discussões que permeiam a Educação Ambiental (EA). Os protagonistas da pesquisa foramos pequenos indígenas Mbyá-Guarani da comunidade da Tekoá Pindó Mirim, localizados em Itapuã/RS. Trata-se de uma pesquisa qualitativa utilizando a cartografia como método de pesquisa-intervenção. Foram utilizadas como estratégias metodológicas na pesquisa: o diário de campo e o registro fotográfico. Os resultados evidenciaram as experiências vivenciadas pelas crianças indígenas no contato com a natureza, as especificidades culturais e as formas variadas de se conceber o papel social dessas crianças dentro da comunidade. $\mathrm{O}$ estudo demonstrou que os "pequenos indígenas" se entrecruzam com a natureza, possibilitou perceber outras constituições das infâncias, assim como também trouxe contribuições para o campo da Educação Ambiental.

Palavras Chave: naturezas; infâncias; crianças indígenas Mbyá-Guarani.

\section{"Indigenous children" of Tekoá Pindó Mirim and the intersections with nature: contributions to the field of Environmental Education}

\begin{abstract}
This study is aimed at childhood in the contemporary world and its intersections with nature, from the perspective of the Sociology of Childhood, the Anthropology of children, and discussions on Environmental Education (EA). The research protagonists are the Mbyá-Guarani indigenous children of the Tekoá Pindó Mirim community, located in the city of Itapuã, State of Rio Grande do Sul, Brazil. It is a qualitative research using cartography as an intervention-research method. Field journal and photographic record were used as methodological strategies. Results show the experiences of indigenous children in the contact with nature, their cultural specificities, and the varied ways of conceiving the social role of these children within the community.

\footnotetext{
1 Pedagoga. Mestranda em Educação Ambiental pela Universidade Federal do Rio Grande - FURG. E-mail: luzinhasansilva@yahoo.com.br

${ }^{2}$ Pedagoga. Mestre e Doutora em Educação Ambiental. Professora Adjunta do Instituto de Educação da Universidade Federal do Rio Grande - FURG. Pesquisadora do Núcleo de Estudos em Educação da Infância - NEPE. E-mail: narjaramg@yahoo.com.br
} 
Therefore, the study shows that indigenous children are connected with nature, making it possible to perceive other constitutions of childhood, as well as contributing to the field of Environmental Education.

Keywords: natures; childhood; Mbyá-Guarani indigenous children.

\section{Introdução}

A temática central desse artigo está relacionada com estudos na área da educação, no âmbito da linha de pesquisa em Educação Ambiental (EA) com foco na concepção de múltiplas infâncias, mais especificamente com a realidade das crianças indígenas e seus entrecruzamentos com a natureza.

A década de 1980 é o marco histórico em que as questões relacionadas à infância passam a ser discutidas e problematizadas. Esse artigo visa ser relevante para os estudos relacionados à infância e Educação Ambiental. Pretende problematizar a concepção de criança/aluno e de seres sociais que "virão a ser alguém" (processo de aprendizado e formação dessas crianças/alunos em seres sociais) e apresentar outra forma de conceber a infância através das experiências da infância indígena. Para isto, buscaremos apresentar uma breve revisão bibliográfica com vistas a apresentar um panorama sobre as questões relacionadas à natureza e infâncias. Em seguida, articularemos algumas referências com observações do trabalho de campo junto às crianças Mbyá-Guarani da aldeia (Tekoá) Pindó Mirim, localizada em Itapuã no Rio Grande do Sul.

\section{Fundamentação}

\subsection{Natureza, Infância e Educação Ambiental}

As concepções relacionadas às formas de se perceber a natureza estão atreladas às culturas dos sujeitos. As epistemologias ecológicas se apresentam como novos horizontes de compreensão que visam superar as dualidades modernas, tais como natureza e cultura, mente e corpo e conhecimento e experiência (Carvalho, 2014). A natureza não é algo exterior, ela é parte constitutiva dos seres humanos, conforme Foladori; Taks:

[...] a natureza não pode ser considerada como algo externo, a que a sociedade humana se adapta, mas sim em um entorno de coevolução, no qual cada atividade humana implica a emergência de dinâmicas próprias e independentes na natureza externa, ao mesmo tempo que, em um efeito bumerangue, produz impactos na natureza social e na biologia das populações humanas (FOLADORI; TAKS, 2004, p.326).

Essa complexidade de interconexões é relevante para estudar os sujeitos e seus entrecruzamentos com a natureza. De acordo com Carvalho "Não se trata aqui de apenas 
reconhecer a diversidade cultural e levar em conta o ponto de vista do 'outro' humano, mas de considerar o ponto de vista das coisas e dos organismos não humanos que habitam o mundo" (CARVALHO, 2014, p. 326).

Ao se trabalhar questões relacionadas à infância e a natureza, a temática do ambiente surge como aspecto relevante. Perceber o ambiente como algo agregado em que a criança não existe sem o mesmo ao qual ela está inserida. Nessa visão o ambiente percebido em sua totalidade, ou seja, se articular as questões naturais, culturais, espaciais e temporais em que os seres humanos são concebidos historicamente e habitam determinado território (SATO, 1997). Segundo Tomás: "Neste contexto as crianças têm sido um dos grupos sociais que tem permanecido sistematicamente fora dos espaços de discussão e participação, ainda que seja um dos que mais sofrem da exclusão e das desigualdades socioeconômicas provocadas pela globalização" (TOMÁS, 2007, p. 76).

Para compreender a perspectiva das crianças indígenas podemos acrescentar a contribuição do conceito de "reprodução interpretativa" (CORSARO, 2011), como um dos fundamentos necessários para entender essas concepções das infâncias indígenas. Conforme o autor, a ideia de interpretativo abarca as questões inovadoras e criativas da participação das crianças na sociedade. E reprodução está relacionada com a ideia de que as crianças não somente internalizam a sociedade e a cultura, mas auxiliam ativamente para produção e modificações culturais. O termo também propõe, conforme Corsaro:

[...] crianças estão por sua própria participação na sociedade, restritas pela estrutura social existente e pela reprodução social. Ou seja, a criança e sua infância são afetadas pelas sociedades e culturas que integram. Essas sociedades e culturas foram, por sua vez, moldadas e afetadas por processos de mudanças históricas (CORSARO, 2011, p.32).

Articulando o conceito de "reprodução interpretativa" proposta por Corsaro (2011) com o campo de discussão da Educação Ambiental, apresentamos as contribuições de Sato (1997) em relação às concepções sobre ambiente. Ao trabalhar com o conceito de ambiente a autora articula o mesmo com a representação social:

[...] é mais relevante estabelecer o conceito de ambiente como uma representação social, isto é, uma visão que evolui no tempo e que depende do grupo social em que é utilizada. São essas representações, bem como as suas modificações ao longo do tempo que importam: é nelas que se busca intervir quando se trabalha o tema ambiente (SATO, 1997, p.3). 
Nesse contexto, o ambiente através das representações das crianças se modifica conforme as internalizações das mesmas e as interpretações que elas fazem, e que representam a sociedade ao qual fazem parte. As realidades por elas vivenciadas são ativas, ou seja, elas transformam também, assim como os adultos o contexto ao qual estão inseridas, realizando representações sociais. Seguindo essa ideia com as contribuições de Reigota: “[...] as representações sociais equivalem a um conjunto de princípios construídos interativamente e compartilhados por diferentes grupos que através delas compreendem e transformam sua realidade" (REIGOTA, 2010, p.71).

Em relação à cultura, Brandão (1985) em "A educação como cultura" traz contribuições ao trabalhar o conceito em que a mesma está vinculada a três aspectos: a compreensão, a reprodução e a transformação todos vinculados ao sistema social. Os seres humanos representam o mundo para si, o interpretam e o constroem e a partir das suas experiências comunicam aos demais. A cultura relacionada a valores de conhecimento, juízo de valores e significação do mundo e dos seres humanos. Segundo o autor aprender tem conexão direta com a participação de vivências culturais que estando presente nesses eventos cada pessoa se reinventa.

Lopes; Vasconcellos (2006) apresentam abordagens das infâncias sob o prisma do artefato cultural e lugar, intitulada: "Geografia da infância", e que vem ao encontro da temática, pois possibilita compreender as circunstâncias sociais que geram a infância em cada localidade. Ao realizar a pesquisa sobre infância indígena é de fundamental importância compreender as questões relacionadas ao pertencimento ao lugar a partir das particularidades daquela determinada aldeia onde, foi realizado o campo de pesquisa, pois conforme os autores:

Compreender como cada realidade elabora a sua ideia de infância e quais são os traços e feixes que a constroem e a tornam válida. Em outras palavras, compreender como cada grupo social, ao estabelecer relações entre seus membros com o espaço que ocupa e com os grupos e espaços diferenciados, estabelece um lugar para as suas crianças, construindo uma subjetividade infantil possível de ser aceita e vivida na subjetividade coletiva do grupo (LOPES; VASCONCELLOS, 2006, p. 104).

A pesquisa com as infâncias indígenas precisa considerar a sua interpretação sobre a natureza, o seu contexto, seus arranjos sociais e culturais naquele determinado espaço e tempo, buscando compreender como os "pequenos indígenas" 3 se apropriam e transformam essas dimensões sociais, criando suas geografias infantis. Didonet

\footnotetext{
${ }^{3}$ Essa é forma como denominam as crianças na aldeia Pindó Mirim.
} 
(2007/2008) aborda em suas pesquisas com a interdependência entre o ser criança e a cultura que atua sobre a mesma e dela recebe influência. Sobre a importância de se confrontar quando estamos falando dessa temática às dualidades universal/particular, global/local e sobre as igualdades/diversidades. Quando se trabalha em pesquisa com criança é fundamental analisar as relações de interinfluência das infâncias e o ambiente sociocultural ao qual pertencem. Conforme Didonet:

As condições econômicas, os valores sociais, as crenças e práticas religiosas, as concepções de mundo e de vida humana, as relações intersubjetivas entram como elementos constitutivos, provocadores, indutores e construtivos do ser criança. Ora, se tais elementos são diversos no tempo e no espaço, as crianças também serão diferentes entre si segundo a cultura, o ambiente, o tempo e a visão de mundo prevalentes onde vivem (DIDONET, 2007/2008, p. 10).

Conforme Didonet, o conceito de infância é uma representação social formada na cultura e interligada as questões socioeconômicas, as concepções de vida, aos valores. As questões de globalização se apresentam, visando homogeneizar a partir da cultura dominante, mas é importante ao se estudar infância se afastar dessa tendência e ir em busca das particularidades.

É verdade que a comunicação e o intercâmbio entre culturas, a hegemonia de uma sobre a outra, a disseminação de valores, comportamentos e padrões de vida de um povo em outros ambientes tendem a homogeneizar, igualar, unificar. Suprimindo as individualidades, suprime-se a riqueza das diferenças e empobrece-se o conjunto, que passa a ser uniforme em torno do que é comum ou daquilo que caracteriza a cultura dominante (DIDONET, 2007/2008, p. 11).

Sobre as questões relacionadas às culturas infantis, as crianças participam das culturas, produzindo-as e se transformando conforme a sociedade ao qual fazem parte. Produzem e são produtoras de culturas "elas elaboram sentidos para o mundo e suas experiências compartilhando plenamente de uma cultura" (COHN, 2005, p.35). Nesse sentido, não existe uma divisão entre cultura do adulto e cultura da criança. A criança e o adulto fazem parte da mesma cultura, no entanto esta cultura pode ser significada e percebida pelos sujeitos de forma diferente, de acordo com o seu repertório e categoria social.

Assim sendo, a pluralidade de culturas infantis se estabelecem no entrecruzamento da produção da infância e da produção do lugar, pois “toda criança é criança de um lugar. Do mesmo modo, toda criança é criança em algum lugar" (LOPES; VASCONCELOS, 2006, p.110). Ao se trabalhar o conceito de lugar trazemos as contribuições de Marandola 
(2014) que diz que a presença, essência do estar-aí, de ser-e-estar-no-mundo, em que esses seres estando em algum lugar específico constituindo seu ser a partir do mundo circundante. "[...] o lugar faz parte de nosso cotidiano e como é a partir dele que nos inserimos no mundo. É pelo lugar que nos identificamos, ou nos lembramos, constituindo assim a base de nossa experiência no mundo" (MARANDOLA, 2014, p. 228). Nesta perspectiva, os estudos relacionados às infâncias, culturas e natureza trazem contribuições ao campo da Educação Ambiental.

Sato; Passos (2011) argumentam que há três esferas multidimensionais dentro do campo da Educação Ambiental que são a natureza, o indivíduo e a sociedade.

A EA, portanto, não é somente o estudo antropológico do ser humano; nem apenas o estudo sociológico da sociedade onde vive; e nem só das relações dos seres vivos com o ambiente, como propõe a ecologia. EA é um diálogo aberto, como um passaporte de trânsito livre que circunda as diversas fronteiras da interação eu-outr@-mundo (SATO; PASSOS, 2011, p. 248).

Sato (2005) trabalha com o conceito de biorregionalismo, que conforme a autora é descrito como: "[...] uma tentativa, entre tantas outras possibilidades, de construir identidades fora dos centros hegemônicos, na relevância das lutas políticas em locais e territórios singulares" (SATO, 2005, p. 41). A Educação Ambiental com foco nas experiências dos lugares, recusando a homogeneidade e considerando os saberes locais e eliminando as hierarquias entre os povos. "A Educação Ambiental inscrita no biorregionalismo reforça que a experiência social é variada e múltipla, e para além do veredicto das alternativas que possibilitem o não desperdício das vivências locais" (SATO, 2005, p. 41).

Os estudos etnográficos dentro do campo da antropologia da criança vêem a contribuir com a modificação da homogeneidade ao se tratar de globalização, já que em cada localidade há uma especificidade de infância e a criança traz consigo as experiências sociais e o repertório que a torna única. Sarmento (2007) argumenta que vários autores:

[...] têm chamado a atenção para a diversidade das formas e modos de desenvolvimento das crianças, em função da sua pertença cultural - isto é, sustentam que a cultura molda a infância, por contraponto à ideia de uma natureza universal da infância, suposta a partir de estudos centrados no Ocidente (SARMENTO, 2007, p. 28).

Fazendo aproximações com a temática de pesquisa, para as comunidades indígenas não existe separação entre cultura-natureza-sobrenatureza, pois estes três conceitos estão 
indissociados em uma teia de relações, diferentemente da sociedade Juruá (branca). Segundo Assis (2006) “[...] para as populações ameríndias, não há dicotomia culturanatureza, pautada na polarização sujeito-objeto como é vista na nossa sociedade. Nas sociedades indígenas, a percepção seria a de relações entre subjetividades" (ASSIS, 2006, p. 80). Seguindo com as articulações de Assis, os Mbyá-Guarani entendem as relações com o ambiente como uma conexão entre subjetividades. As coisas naturais não são consideradas coisas objetivadas. Na perspectiva deles cada elemento do ambiente (vegetais, animais, eles mesmos) possui uma matriz original situada no mundo divino (ASSIS, 2006, p. 83).

Ao se realizar pesquisa no campo da Educação Ambiental como pesquisadoras buscamos trazer na escrita do artigo o lugar ao qual vivenciamos a pesquisa sujeitos/sujeitos e não o espaço como algo abstrato, mas o lugar, a aldeia Tekoá Pindó Mirim com suas características e singularidades que a torna única. Conforme Grün: "a questão que se coloca para a Educação Ambiental é como fazer uma reapropriação social dos lugares para podermos ter uma noção de lugar e assim engendrar práticas mais orientadas ecologicamente e mais situadas" (GRÜN, 2008, p. 4). O sentimento de pertença, aproximação com o campo de pesquisa com o intuito de compreender as peculiaridades dos "pequenos indígenas" e suas interações com o ambiente são fundamentais quando estamos tratando de lugar. "Estar em um lugar, ter a 'noção de lugar' é um modo de pertença ao mundo e é importante para nossa percepção primária e interconexões com o mundo não humano" (GRÜN, 2008, p.8). Pertencimento, lugar, cultura, pesquisa com e não sobre são alguns dos pontos trabalhados na pesquisa tornando a mesma viva, pulsante, onde o que se encontra e aprende são desvelados durante o processo, construindo o texto no coletivo juntamente com os sujeitos da pesquisa.

\section{Metodologia}

Apropriamo-nos da cartografia como método de pesquisa-intervenção, proposto por Passos; Kastrup; Escóssia (2015) no livro "Pistas do método da cartografia: Pesquisaintervenção e produção de subjetividade", que se apresentou como referencial base para compreensão sobre esse método. Definindo o método a partir do primeiro capítulo do livro, Passos; Barros:

A cartografia como método de pesquisa-intervenção pressupõe uma orientação do trabalho do pesquisador que não se faz de modo 
prescritivo, por regras já prontas, nem com objetivos previamente estabelecidos. No entanto, não se trata de uma ação sem direção, já que a cartografia reverte o sentido tradicional de método sem abrir mão da orientação do percurso da pesquisa (PASSOS; BARROS, 2015, p.17).

Segundo esse método toda pesquisa é intervenção, um adentrar do cartógrafo na experiência em campo, impossível à neutralidade não se separando conhecer e fazer. $\mathrm{O}$ observador atuante interfere e modifica as situações e os sujeitos da pesquisa. Sendo percebido como um método maleável, pois vai trilhando caminhos sem serem prescritos de antemão.

Nesse sentido, conhecer a realidade é acompanhar seu processo de constituição, o que não pode se realizar sem uma imersão no plano da experiência. Conhecer o caminho de constituição de dado objeto equivale a caminhar com esse objeto, constituir esse próprio caminho, constituir-se no caminho. Esse é o caminho da pesquisa-intervenção (PASSOS; BARROS, 2015, p.31).

O pesquisador "cartógrafo" ao chegar a campo se prepara para algumas delineadas do que pretende observar, se prepara. Entretanto, as expectativas devem ser abandonadas no momento de entrada, pois para encontrar o que não conhece é necessário uma atenção e olhar sensível, sem respostas prontas senão a pesquisa não tem sentido. O conhecimento irá se produzir não a partir de uma realidade preexistente, dominado e sim irá surgir como composição no acompanhamento de processos (KASTRUP, 2015).

O caminho da pesquisa cartográfica é composto por passos que se sucedem. Nesse movimento contínuo a pesquisa vai se constituindo nessas marcas desde, o início da pesquisa. No processo presente em todos os momentos na coleta, na análise, nas reflexões sobre os dados produzidos e na escrita final sobre o que foi experienciado (BARROS; KASTRUP, 2015).

Por conseguinte, conforme esse método não se realiza coleta de dados, pois o termo mais adequado é produção de dados. Elas justificam essa mudança de nomenclatura devido ao fato de que desde a etapa inicial da pesquisa está se produzindo. Conforme Kastrup:

É preciso sublinhar que esse processo continua com as etapas posteriores, atravessando as análises subsequentes dos dados e a escrita dos textos, continuando ainda com a publicação dos resultados. Para sermos bastante precisos, seria necessário incluir também a circulação do material escrito e a própria leitura do mesmo pelos interessados, tudo isso sem falar na contribuição dos participantes da pesquisa na produção coletiva do conhecimento (KASTRUP, 2015, p.48).

$\mathrm{Na}$ pesquisa de campo estar aberta para novas aprendizagens e concepções de infância, buscando construir uma relação de troca, buscando tratar os "pequenos 
indígenas" sem relações adultocêntricas. Cohn ao trabalhar em seu livro "Antropologia da criança” com questões metodológicas e técnicas de pesquisa diz que:

[...] seu caráter dialógico, de interação, terá que ser enfatizado, permitindo ao pesquisador tratar as crianças em condições de igualdade e ouvir delas o que fazem e o que pensam sobre o que fazem, sobre o mundo que as rodeia e sobre ser criança, e evitando que imagens 'adultocêntricas' enviesem suas observações e reflexões. Significa lembrar, desde a realização da pesquisa (e não apenas na análise dos dados), que a criança é um sujeito social pleno, e como tal deve ser considerada e tratada (COHN, 2005, p.45).

O diário de campo foi utilizado como um instrumento metodológico nas saídas de campo. No mesmo há relatos das diferentes experiências vivenciadas juntamente a comunidade indígena, mais intensamente com os "pequenos indígenas" da aldeia.

Outra estratégia de registro foi a fotografia sendo, utilizada como estratégia metodológica a partir do uso da imagem enquanto, registro de pesquisa. As fotos foram complementares as observações e os "pequenos indígenas" puderam fotografar e interpretar as imagens a partir do olhar deles sobre a realidade ao qual fazem parte. Em relação à fotografia, segundo Andrade “[...] A fotografia, como um meio de expressão, pode nos fornecer uma visão ampliada das coisas alheias" (ANDRADE, 2002, p.26).

$\mathrm{Na}$ pesquisa foram utilizadas diversas fotografias registradas nas incursões em campo, com o objetivo de ilustrar as situações relatadas. A partir da observação das fotografias foi possível escrever as reflexões sobre os dados produzidos em campo e algumas análises sobre as mesmas. Trazendo as contribuições de Andrade:

[...] a imagem fotográfica nasce da observação de uma realidade que está contida em uma estrutura cultural, ela vem carregada de significados, de fragmentos que deverão ser moldados em um relato único e revelador. A imagem comunga com o texto para nos fazer melhor compreender e elaborar uma análise desses significados (ANDRADE, 2002, p.52).

Optamos também, por utilizar como instrumento de pesquisa filmagens do cotidiano dos pequenos indígenas na aldeia. $\mathrm{Na}$ busca por captar o olhar deles sobre essas vivências foram convidados a fazerem suas gravações de forma espontânea a partir de situações vivenciadas na aldeia. Os nomes presentes no artigo são fictícios, com o intuito de preservar a identidade dos interlocutores. 


\section{Resultados e discussões}

3.1 Os entrecruzamentos da infância indígena com a natureza

A separação que fazemos hoje entre 'natureza' e 'sociedade' ou 'natureza e 'cultura, herança do pensamento filosófico e do empirismo, é impraticável para o pensamento indígena (CARRARA, 2002, p. 114).

Nessa parte do artigo iremos trazer alguns elementos, indícios das experiências no trabalho de campo junto à comunidade da Tekoá Pindó Mirim com o intuito de descrever o universo que circunscreveu a pesquisa. O foco será nos "pequenos indígenas" e na sua comunidade que está articulada em uma teia de relações e, o trabalho desenvolvido pretende mostrar essas interconexões.

Uma das categorias que emergiram da análise dos dados produzidos nas interações na aldeia aponta para os entrecruzamentos entre as crianças com a natureza. As reflexões e análises são um apanhado das leituras feitas a partir de referenciais teóricos que trabalharam sobre a temática da cultura guarani e mais especificamente sobre as crianças indígenas conjuntamente com as leituras realizadas sobre Educação Ambiental fazendo relações com observações em campo e as contribuições da comunidade da Tekoá Pindó Mirim para o referido estudo.

Um conceito que foi trabalhado como produção dos dados e subcategoria da pesquisa foi os entrecruzamentos com a natureza, a partir da perspectiva de que os indígenas da Tekoá Pindó Mirim são natureza, não havendo essa dicotomia e separação. Refletimos a partir dos entrecruzamentos entre humanos e não humanos tendo como ponto de partida essa concepção da não dualidade, as intersecções entre todos os seres (humanos e não humanos) e os ambientes. Segundo Carrara:

Mais do que uma observação atenta dos animais, plantas e outros elementos do céu e da terra, os índios e alguns habitantes do campo têm uma visão integrada dos seres e ambientes, entre os quais estão permanentemente inseridos e profundamente entrelaçados para poder entender e agir sobre uma natureza que está em constante movimento (CARRARA, 2002, p.115).

A dicotomia seres humanos-natureza, a partir de uma visão antropocêntrica, não é algo partilhado pela comunidade indígena na qual realizamos o campo de pesquisa. Durante diversas situações percebemos a conexão com a natureza em que a mesma faz parte da constituição do ser indígena e as aprendizagens ocorrem no e com o ambiente. 
Sato \& Passos ao descreverem os habitantes de Mimoso, comunidade pantaneira se aproximam das explanações acima e contribuem ao relatar que:

São parte da natureza, suas raízes estão interpenetradas nela, de sorte que a visão modernista do mundo-objeto, como alteridade distinta do sujeito, é absolutamente desprezada. O que aprendem na natureza é necessariamente inferido para o mundo do conhecimento (SATO; PASSOS, 2011, p.248).

A partir das visitas mais frequentes à aldeia, em que o vínculo e confiança já estavam formados, foi possível observar estas interações entre as crianças indígenas com a natureza, como expresso no relato a seguir:

"Iniciamos nossas filmagens e realizamos uma trilha. As crianças bem na frente adentraram no mato e João disse que algumas dela já entram no mato e se acham sozinhas. Chegamos a um ponto em que havia um barranco bem íngreme para subir. Como havia chovido há poucos dias estava com muito barro. As crianças subiam com uma desenvoltura impressionante. Brincavam de se pendurar nos cipós, subir e descer várias vezes, era uma sincronicidade com a natureza, felizes naquele momento, eles e a natureza eram como encaixes de quebra cabeça era lindo de se ver. Dava para perceber o quanto aquilo fazia sentido para eles algo que apreciavam, eles fazendo parte da natureza. Eles enquanto se penduravam faziam gritos como do Tarzan. Era visível de perceber o corpo como instrumento para aprendizagem, a interação do mesmo fazendo parte da natureza" (diário de campo - 09/09/2016). ${ }^{4}$

O processo educativo que atravessa o corpo na vivência, na prática e se torna conhecimento. Subir aquele íngreme barranco necessitava de desenvoltura, conhecimento sobre as plantas (em qual local segurar, como manter o corpo inclinado) reconhecimento do corpo e habilidade para desenvolver tal tarefa, algo que os "pequenos indígenas" desempenhavam com facilidade. São tarefas e atividades que se mostram habituais e que, por isso, demonstram o vínculo dessas crianças com o habitat natural.

Ao refletir sobre essa experiência com os "pequenos indígenas" no trajeto da trilha, foram perceptíveis os atravessamentos que ocorrem entre os seres vivos indígenas, o meio natural e outros seres vivos. Suas concepções de mundo são percebidas, vivenciadas no ser conectado aos outros elementos do planeta. Carrara contribui com as análises ao dizer que:

As árvores e outras plantas não são meros vegetais, estáticos, que podem ser entendidos sem o filtro das concepções culturais e das relações

\footnotetext{
${ }^{4}$ As aspas foram utilizadas para identificar os trechos retirados do diário de campo.
} 
sociais. Ao contrário, elas são percebidas, ordenadas, classificadas, associadas e interpretadas de acordo com modos próprios (específicos) de concepção de mundo. São cultivadas, usadas na vida cotidiana, nas curas medicinais, na caça, na alimentação e estão sempre presentes e, representações simbólicas (discursos, narrativas, mitos, etc.) dos povos indígenas. Muito mais do que uma importância ambiental (ecológica), plantas, animais, terra, céu, estrelas, outros elementos cosmográficos e o próprio Homem são pensados pelos índios em um conjunto de múltiplas inter-relações que envolvem saberes, técnicas e uma constante interpenetração intelectual e prática entre natureza e sociedade (CARRARA, 2002, p.114).

Por conseguinte, outra questão importante é sobre o corpo como elemento essencial para a aprendizagem e a relação dos seres indígenas com a natureza. Havia sincronicidades entre os movimentos dos corpos das crianças com os elementos naturais. Silva (2002) desenvolveu pesquisa com os $A$ 'uwê focando em suas pesquisas a importância do corpo para essa comunidade com quem trabalha. A autora argumenta que: "Uma primeira lição que essas crianças $A$ 'uwê nos ensinam é que se aprende vivendo, experimentando e que o corpo, suas sensações e seus movimentos são instrumentos importantes do aprendizado e da expressão dos conhecimentos em elaboração" (SILVA, 2002, p. 42). Conforme podemos perceber com a imagem a seguir.

Figura 01: Trilha na aldeia.

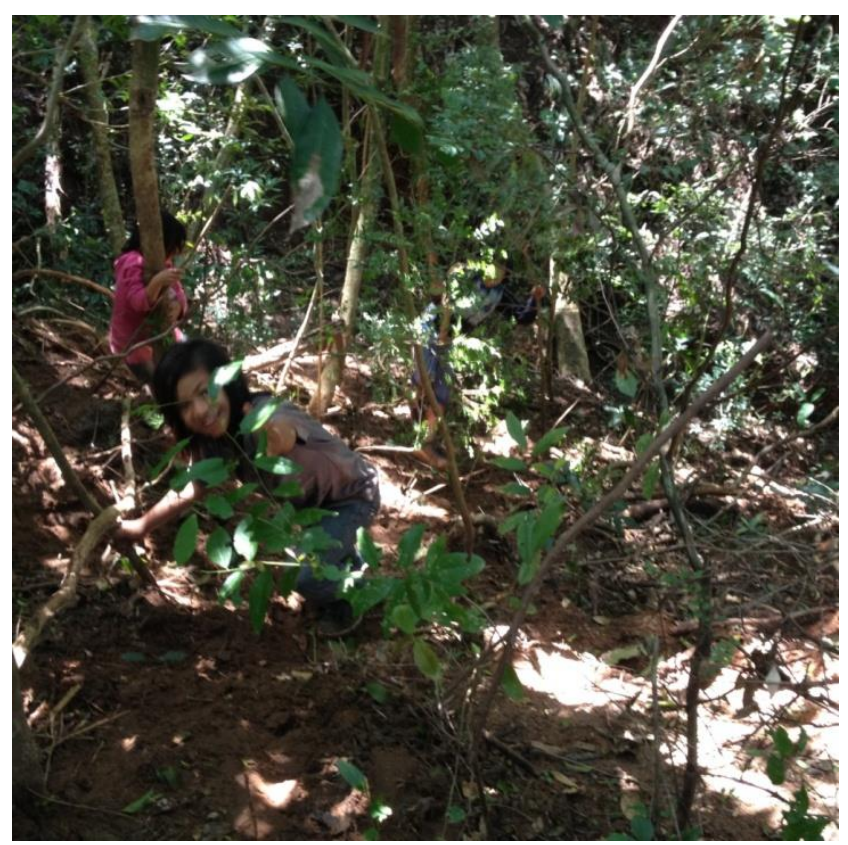

Fonte: Produzido pela autora; Data: 06/09/2016

As crianças da aldeia Pindó Mirim foram percebidas como protagonistas de suas vidas, atores sociais plenos e ativos dentro do contexto do cotidiano da aldeia e eram respeitadas e consideradas pelos adultos da comunidade. 
"Em uma das incursões a campo a comunidade estava nos preparativos para a Semana Cultural, em que escolas e pessoas interessadas agendam com a Nhamandu Nhemopu'ã para passar um dia participando das atividades da Tekoá Pindó Mirim e tendo a oportunidade de conhecer a cultura dos Mbyá-Guarani da respectiva comunidade. Nessa manhã, os integrantes da escola e a comunidade em geral participavam ativamente em diferentes afazeres, como roçar a terra, identificar as árvores em guarani com as placas construídas com madeira e pirógrafo. Ao observar os 'pequenos indígenas', percebi suas autonomias e responsabilidades para com o trabalho. Em nenhum momento era um adulto que 'comandava' as atividades, os 'pequenos indígenas' trabalhavam espontaneamente e na atividade em que julgavam ser necessária sua participação e interesse" (diário de campo - 24/03/2016).

Gomes contribui ao dizer que: “[...] são as próprias crianças que muitas vezes se propõem a participar de alguma atividade “(...) Tais formas de participação funcionam como situações de aprendizagem in loco" (GOMES, 2009, p.88). Suas autonomias e responsabilidades foram visíveis ao olhar das pesquisadoras. Essas contribuições apresentam outra forma de se perceber a infância a partir do local onde vivem, que permitem acrescentar e aprofundar os estudos sobre as multiplicidades das infâncias e contribuem para o campo de pesquisa com crianças.

Outro momento nesse estudo perceptível dos entrecruzamentos das infâncias indígenas com a natureza foi quando as crianças prepararam a culinária típica guarani. Nas incursões em campo na Tekoá Pindó Mirim existe uma cultura de respeito e valorização dos "produtos" da natureza que é transmitida através das gerações. Nesta atividade cultural não existe uma exploração desenfreada dos recursos naturais, pois eles utilizam somente o necessário para viver na comunidade, o que demonstra um aprendizado de proteção e interação harmoniosa com os elementos da natureza.

"Havia proposto há alguns dias atrás de fazermos uma culinária típica e eles aceitaram e me indicaram os ingredientes para levar. Cheguei à aldeia e vários meninos carregavam toras de madeira para fazer o fogo. As mulheres preparavam os ingredientes no Espaço Cultural e no centro haviam feito um fogo com as toras de madeira. Interessante de perceber que utilizavam diversos elementos da natureza no preparo dos alimentos (colher de pau feita de bambu, bambu para preparar o alimento 'cocô de macaco', tronco feito de pilão). O clima era de descontração, risadas, música, crianças brincando. No dia da preparação da culinária a ideia de eles filmarem foi bem aceita. A máquina passava de mão em mão, várias pessoas filmaram e tiraram fotos. Vi que eles apreciaram a minha ideia. $\mathrm{O}$ 
clima era de festa, vieram participar diversas pessoas que moram na aldeia, que eu não conhecia. Cada um contribuía de seu jeito, mulheres cozinhavam, ninguém comandava a situação, era como se cada integrante soubesse seu papel, reconhecesse sua função na cena que acontecia. Crianças corriam, brincavam de bola de gude, alguns homens sentados observavam, outros tocavam instrumentos e cantavam canções guarani, o fogo acesso e a fumaça que subia tornava o ambiente acolhedor e fluido. Diferentes elementos naturais faziam parte do contexto, fogo, madeira, água, alimentos produzidos pela terra. Diversas formas de conhecimento se apresentavam naquele momento de festividade, o saber ancestral das mulheres no preparo dos alimentos, em que as meninas mais novas observavam e aprendiam. O conhecimento que a arte proporciona através da música entoada nos cantos e na exploração dos instrumentos. A interdisciplinaridade dialogava sutilmente naquele contexto de educação e confraternização" (diário de campo 22/09/2016).

Stumpf; Wolf; Bergamaschi, ao tratarem sobre ambiente e cultura para os MbyáGuarani:

\begin{abstract}
A ligação entre ambiente e cultura proporciona a integração entre os diversos aspectos que compõem a vida humana, e sua manifestação no cotidiano Mbyá, em uma forma de vida em que aspectos como economia, saúde, educação, organização social e política estão integrados na relação humana com a natureza. Esta visão pode ser dialogada com a concepção sistêmica, trazida em algumas abordagens da EA. Neste sentido a interdisciplinaridade também se apresenta como um princípio importante, em um movimento de diálogo e interação entre diferentes formas de conhecimento (STUMPF; WOLF; BERGAMASCHI, 2016, p. 256).
\end{abstract}

A experiência de culinária e confraternização destacada no diário de campo foi um momento de festividade. Esta pode ser percebida como uma atividade cultural vivenciada pelas crianças, em que os processos educativos sobre os elementos naturais podem ser aprendidos e experienciados no cotidiano da comunidade. Essas aprendizagens ocorriam sutilmente e de forma interdisciplinar dialogando com diferentes áreas do conhecimento e acessando-as de forma interligada, conforme podemos visualizar com a imagem a seguir: 
Figura 02: Mulheres da aldeia cozinhando comidas típicas

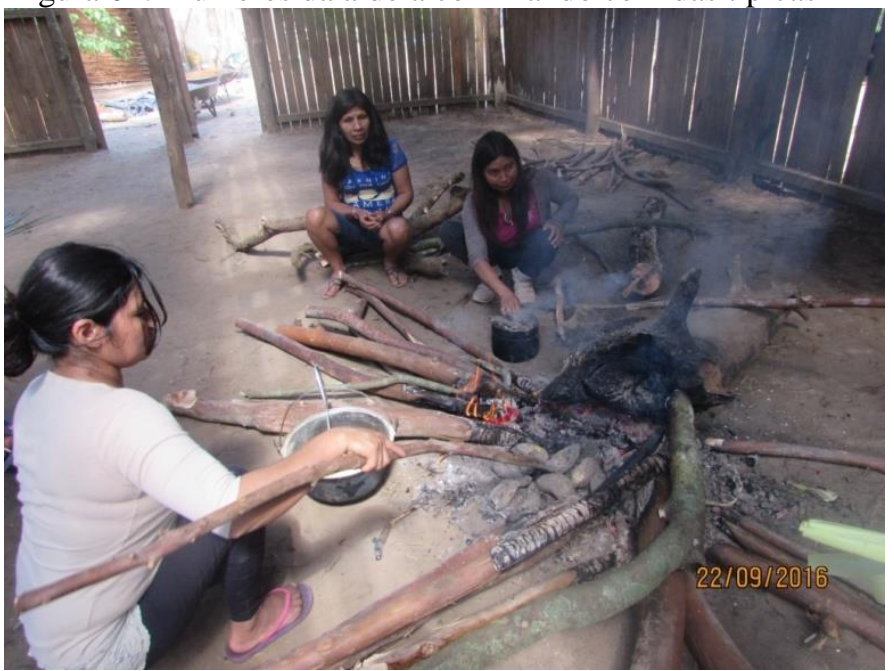

Fonte: Própria autora; Data: 22/09/2016

Outro aspecto relacionado ao ambiente e as expressões culturais dos indígenas tem relação com a vida comunitária que se modifica conforme as estações do ano, assim como também o processo lúdico em que as brincadeiras têm relação com a sazonalidade. A comunidade se move nos fluxos ambientais conectados as mudanças climáticas, aos sinais que a natureza apresenta.

“Uma das brincadeiras apreciadas pelos 'pequenos indígenas' é o jogo com bolas de gude. Em diversas incursões em campo pude observar crianças, não sei se por coincidência ou o jogo está relacionado com gênero, em todas às vezes eram meninos que realizavam a brincadeira. Aspectos que merecem atenção são: a habilidade pessoal para ter sucesso na jogada, por ser um jogo de concentração, um processo individual, silencioso. Mesmo sendo uma brincadeira coletiva cada participante se focava na sua jogada estratégica, no seu movimento de corpo para ter sucesso com a jogada da bola de gude. Uma brincadeira realizada em dias quentes e secos, para que a bola de gude deslize no chão e o jogo possa se desenvolver de forma adequada" (diário de campo -11/03/2016).

Sobre essa sazonalidade Nunes afirma:

A vivência da sazonalidade implica, igualmente, tecer diferentes relações de espaço e tempo, nas quais a vida doméstica, a produção familiar e a organização comunitária encaixam-se e desdobram-se ao longo do ano, em arranjos que refletem também etapas do ciclo de vida de cada indivíduo (NUNES, 2002, p. 79). 
A vida comunitária flui assim, como as estações do ano com suas particularidades. Em dias de temperatura agradável se reúnem em círculo para tomar chimarrão e conversar e que são momentos em que as risadas estão presentes, tornando o ambiente acolhedor. Mulheres e meninas aproveitam o calor para lavar em cócoras as roupas trabalhando de forma espontânea e tranquila, enquanto crianças pequenas brincam no entorno. Cada integrante com seu fazer cotidiano individual e ao mesmo tempo coletivo, em que todos cuidam e auxiliam a todos. Assim, a vida na aldeia vai se constituindo, sem tempo preestabelecido ou preocupações com a vida acelerada. A vida flui nos ciclos das estações, a imagem a seguir apresenta a estação verão.

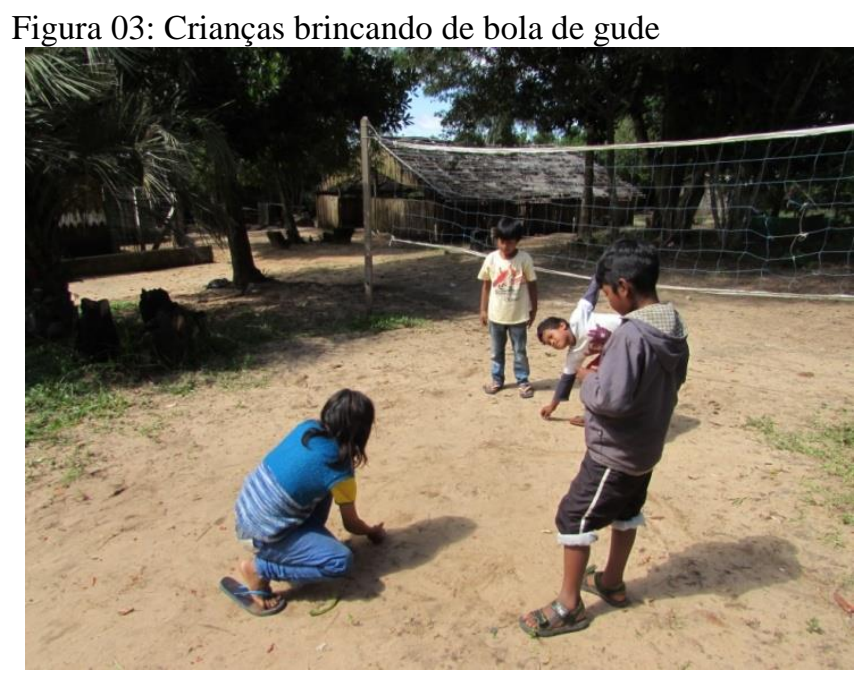

Fonte: Própria autora; Data: 11/03/2016

As brincadeiras lúdicas têm relação direta com a cultura a quais as crianças fazem parte. $\mathrm{Na}$ imagem acima os "pequenos indígenas" brincam de bola de gude, utilizam o corpo para que ocorram aprendizagens. Uma brincadeira estratégica e corporal (força do movimento, posição do corpo, concentração, etc.) são aspectos importantes para o jogo. Brougère, autor da sociologia da infância, desenvolve pesquisa sobre o brinquedo e a produção cultural infantil. Argumenta que: “[...] o brinquedo como suporte de brincadeira requer a impregnação cultural e a socialização da criança no mundo em que vive" (BROUGÈRE, 2013, p.88). Ou seja, os "pequenos indígenas" utilizam de brinquedos e de brincadeiras tradicionais, muitas vezes com elementos da natureza transformados em produtos da cultura indígena, a qual fazem parte. 


\section{Considerações finais}

Com a pesquisa realizada foi possível atentar para outras constituições de infâncias e outra relação com a natureza. Com o intuito de proporcionar aos educadores/leitores/pesquisadores uma desestabilização da zona de conforto e, através de questionamentos que nos acompanharam durante a pesquisa demonstrar, com vivências e experiências na aldeia, outras concepções sobre infâncias e natureza. Instigamos a algumas reflexões e mudanças na forma de pensar e agir. Somos pessoas aprendentes e nesse processo evolutivo que é a vida podemos nos modificar com a coragem de inovar, contribuindo para com aquilo que acreditamos.

Através dos estudos da sociologia da infância e antropologia da criança temos conhecimento que existe uma multiplicidade de infâncias, que está intimamente relacionado ao contexto das mesmas, do local onde vivem, pertencentes a diferentes culturas.

Com os resultados das incursões em campo, podemos perceber claramente o quanto as crianças são importantes para a comunidade, são percebidas como atores sociais plenos que participam ativamente na rotina da aldeia. Diferente da concepção de preparação para a vida adulta as crianças são respeitadas e consideradas enquanto seres vivos que ensinam e aprendem. A aprendizagem é focada principalmente no corpo, não somente nos aspectos mais cognitivos como percebemos acentuados na sociedade industrial. $O$ processo educativo tem que passar pelo corpo a partir da aprendizagem in loco, no aprender ao observar e fazer. Não existem restrições no sentido de ser perigoso, de as crianças não terem capacidade.

Outros aspectos comuns entre as crianças da aldeia são a liberdade e a autonomia. Transitam livremente por diferentes espaços, decidem suas ações no ambiente, resolvem sozinhas seus conflitos. Inicialmente, algumas situações observadas podem causar estranhamentos e julgamentos a partir da concepção de infância que possa demonstrar o pesquisador, pelo fato de não ser parte daquele lugar e sim, de outro local com concepções de infância diferenciada. Após, o contato e estudo com os "pequenos indígenas" foi possível construir novas experiências e compreender esse outro contexto de percepção e realidade de infância. Os "pequenos indígenas" são alegres, autônomos e responsáveis pelos seus atos. Brincam e desenvolvem atividades em conjunto com os adultos, com o mesmo comprometimento e satisfação. Cuidam uns dos outros sem qualquer intervenção de um adulto. Dividem suas tarefas, seus alimentos, vivendo em harmonia no coletivo. 
Quando falamos sobre educação, um tema amplo e bastante diverso é necessário se contextualizar a realidade sobre a qual se está realizando pesquisa. Os processos educativos estão relacionados à cultura a qual os seres fazem parte, portanto existem múltiplas maneiras de se perceber o ambiente que os cerca. Por exemplo, a forma de se perceber a natureza por uma criança que vive em apartamento em um centro urbano e diversa da forma como é percebida por um pequeno indígena de uma aldeia. Relacionar tal fato com a temática da Educação Ambiental é de fundamental importância se ter claro o contexto, os lugares onde se pretende realizar o processo educativo. Assim como as infâncias, que são diversas e múltiplas não se pode falar somente em uma Educação Ambiental, já que as realidades vivenciadas pelos seres humanos são variadas.

$\mathrm{Na}$ aldeia, como já mencionado acima as aprendizagens são vivenciadas através do corpo considerando os seres humanos de forma integral. Seres, natureza e sobrenatureza se entrecruzam e a Educação Ambiental é um processo espontâneo e vivenciado na rotina da comunidade.

Essas outras realidades, em que a aprendizagem ocorre ao se considerar os seres humanos de forma integral nos possibilitam rever metodologias e práticas educativas em Educação Ambiental. A Educação Ambiental comportamentalista, apresentando temas fragmentados, percebendo o educador como central no processo educativo, personagem que ensina como os outros devem agir perante os elementos naturais não atinge transformações que consigam mudanças significativas. Aprender com os indígenas na forma como se relacionam com a natureza e na interação entre pares na comunidade é uma pista para atingirmos uma Educação Ambiental mais significativa, atuante e contextualizada.

Ao buscar compreender essas infâncias vividas por essas crianças que aprendizagens podemos ter no sentido não apenas do apontamento das limitações da nossa educação, mas na indicação das potencialidades de valores que daí emergem com possibilidades de ressignificar não apenas a infância mas também uma Educação Ambiental das infâncias que tem como pano de fundo os saberes dessa comunidade? Que essas questões fiquem ecoando dentro de nós.

\section{Referências}

ANDRADE, Rosane de. Fotografia e Antropologia: olhares fora/dentro. São Paulo: Estação Liberdade/EDUC, 2002. 
ASSIS, Valéria Soares de. Dádiva, mercadoria e pessoa: as trocas na constituição do mundo social Mbyá Guarani. 2006. 326f. Tese (Doutorado em Antropologia Social) Programa de Pós-Graduação em Antropologia Social, Universidade Federal do Rio Grande do Sul, RS, 2006.

BARROS, Laura Pozzana; KASTRUP, Virgínia. Cartografar é acompanhar processos. In: Pistas do método da cartografia: Pesquisa-intervenção e produção de sujetividades/Org. Eduardo Passos, Virgínia Kastrup e Liliana da Escóssia, Porto Alegre: Sulina, 2015.

BRANDÃO, Carlos Rodrigues. A educação como cultura, São Paulo: Brasiliense, 1985.

BROUGÈRE, Gilles. O brinquedo e a produção cultural infantil. Revista Educação, Especial Cultura e Sociologia da infância. 2013.

CARRARA, Eduardo. Um pouco da educação ambiental Xavante. NUNES, Angela. In Crianças indígenas: ensaios antropológicos. $1^{\mathrm{a}} \mathrm{ed}$. São Paulo: Global, 2002.

CARVALHO, Isabel Cristina de Moura. Epistemologias Ecológicas: delimitando um conceito. Mana. v. 20, n.1, p. 163-183, 2014.

COHN, Clarice. Antropologia da criança. Rio de Janeiro: Zahar, 2005.

CORSARO, William Arnold. Sociologia da infância. Tradução: Lia Gabriele Regius Reis, Porto alegre: Artmed, 2011.

DIDONET, Vital. Um olhar histórico e antropológico sobre a infância e a cultura. Revista Pátio Educação Infantil. Educação Infantil e Cultura. Ano V, n. 15, p. 10-13, nov./fev. 2007/2008.

FOLADORI, Guilhermo; TAKS, Javier. Um olhar antropológico sobre a questão ambiental. Mana, v.10, n. 2, p.323-348, 2004.

GOMES, Ana Maria Rabelo. Outras crianças, outras infâncias? In: Estudos da infância: educação e práticas sociais. Manuel Sarmento, Maria Cristina Soares de Gouvea (orgs.) 2a edição, Rio de janeiro: Vozes, 2009.

GRÜN, Mauro. A importância dos lugares na Educação Ambiental. Revista eletrônica Mestrado em Educação Ambiental. v. especial, dezembro de 2008.

KASTRUP, Virgínia. O funcionamento da atenção no trabalho do cartógrafo. In: Pistas do método da cartografia: Pesquisa-intervenção e produção de sujetividades/Org. Eduardo Passos, Virgínia Kastrup e Liliana da Escóssia, Porto Alegre: Sulina, 2015.

LOPES, Janer Moreira; VASCONCELLOS, Tânia. Geografia da infância: Territorialidades Infantis. Currículo sem fronteiras, v. 6, n. 1, p.103-127, jan./jun. 2006.

MARANDOLA, Eduardo Jr. Lugar enquanto circunstancialidade. In: Qual o espaço do lugar?: geografia, epistemologia, fenomenologia, Org. Eduardo Marandola Jr., Werther Holzer, Lívia de Oliveira. São Paulo: Perspectiva, 2014.

NUNES, Ângela. No tempo e no espaço, brincadeiras das crianças A'uwe-Xavante. In: Crianças indígenas ensaios antropológicos, 2002.

PASSOS, Eduardo; BARROS; Regina Benevides. A cartografia como método de pesquisaintervenção. In: Pistas do método da cartografia: Pesquisa-intervenção e produção de subjetividades/Org. Eduardo Passos, Virgínia Kastrup e Liliana da Escóssia, Porto Alegre: Sulina, 2015.

REIGOTA, Marcos. Meio ambiente e representação social. $8^{a}$ edição. São Paulo: Cortez Editora, 2010. 
SARMENTO, Manuel Jacinto. Visibilidade social e estudo da infância. Infância (in)visivel/ vera Maria Ramos de Vasconcellos, Manuel Jacinto Sarmento, organizadores, Araraquara, SP.: Junqueira \& Marin, 2007.

SATO, Michèle. Biorregionalismo: a educação ambiental tecida pelas teorias biorregionais. In: Encontros e caminhos: formação de educadoras (es) ambientais e coletivos educadores. Brasília, 2005.

Educação para o Ambiente Amazônico. 2006. 246f. Tese (Doutorado em Ciências) - Programa de Pós-Graduação em Ecologia e Recursos Naturais, Universidade Federal de São Carlos, 1997.

SATO, Michèle; PASSOS, Luiz Augusto. Biorregionalismo: identidade histórica e caminhos para a cidadania. In: Educação Ambiental: repensando o espaço da cidadania, Cortez, 2011.

SILVA, Aracy Lopes da. Pequenos "xamãs": crianças indígenas, corporalidade e escolarização. NUNES, Angela. In Crianças indígenas: ensaios antropológicos. $1^{\mathrm{a}}$ ed. São Paulo: Global, 2002.

STUMPF, Beatriz Osorio; WOLF, Denise Rosana E BERGAMASCHI, Maria Aparecida. Reflexões interculturais sobre educação ambiental indígena. Revista Eletrônica Mestrado em Educação Ambiental - REMEA, v.33 n. 2 p. 247-267, mai/ago. 2016.

TOMÁS, Catarina. Globalização: do reflexo na infância à reflexão com as crianças. In: DORNELLES, Leni Vieira (Org.). Produzindo pedagogias interculturais na infância. Rio de Janeiro: Vozes, p. 71 - 111, 2007. 